\title{
Reduced global longitudinal and radial strain with normal left ventricular ejection fraction late after effective repair of aortic coarctation - a CMR feature tracking study
}

\author{
Shelby Kutty ${ }^{1 *}$, Sheela Rangamani ${ }^{1}$, Jeeva Venkataraman ${ }^{1}$, Ling $\mathrm{Li}^{1}$, Andreas Schuster ${ }^{2}$, Scott E Fletcher ${ }^{1}$, \\ David A Danford ${ }^{1}$, Philipp B Beerbaum ${ }^{3}$
}

From 15th Annual SCMR Scientific Sessions

Orlando, FL, USA. 2-5 February 2012

\section{Background}

Little is known about the state of left ventricular (LV) mechanics long-term after repair of coarctation of the aorta (COA). We sought to determine whether LV myocardial deformation indices measured by cardiac magnetic resonance-based feature tracking (CMR-FT) were abnormal in repaired COA with normal LV ejection fraction (EF), relative to healthy adult controls, and whether such alteration was related to LV hypertrophy.

\section{Methods}

We retrospectively identified 81 patients after COA repair (31 female male; age $25 \pm 8.5$ years) with inclusion criteria at follow-up CMR of: age $\geq 13$ years, time postrepair $\geq 10$ years, no aortic valve disease, $L V-E F>50 \%$ ). CMR-FT was performed in four-chamber and short-axis steady-state free-precession cine sequences to derive global and segmental LV deformation indices and indexed (body surface area, BSA) end-diastolic/end-systolic volumes, mass, and LV-EF. LV deformation and volumetric indices were compared firstly between COA patients and normal controls $(\mathrm{n}=20,10$ female, age $37 \pm 7$ years), and secondly between COA patients with (mass $>97$ th percentile for gender and BSA) versus without LV hypertrophy.

\footnotetext{
'Joint Division of Pediatric Cardiology, University of Nebraska College of Medicine/ Creighton University School of Medicine, Children's Hospital and Medical Center, Omaha, NE, USA

Full list of author information is available at the end of the article
}

\section{Results}

In COA patients versus healthy controls, LV-EF was 62 $\pm 7.2 \%($ mean $\pm \mathrm{SD})$ versus $58 \pm 3.0 \%(\mathrm{p}=0.01)$, and LV mass $66 \pm 16.8 \mathrm{~g} / \mathrm{m} 2$ versus $57.7 \pm 6.0 \mathrm{~g} / \mathrm{m} 2(\mathrm{p}=0.0001)$. The LV global longitudinal strain (GLS) was decreased to $-17.0 \pm 4.7 \%$ in COA versus $-20 \pm 5 \%$ in controls $(\mathrm{p}=0.02)$ and the global radial strain (GRS) was reduced to $40 \pm 15 \%$ versus $50 \pm 12.4 \%$ in controls $(\mathrm{p}=0.003)$. In contrast, the global circumferential strain (GCS) was preserved in COA patients at $-23 \pm 4.7 \%$ versus -24.6 $\pm 2.4 \%$ in controls $(\mathrm{p}=0.14)$. Regionally, decrease in LS was particularly marked in the basal segments (septal, $\mathrm{p}=0.005$ and lateral, $\mathrm{p}=0.013$ ). In COA with LV hypertrophy $(\mathrm{n}=45, \mathrm{LV}$ mass $76.3 \pm 12.8)$ versus $\mathrm{COA}$ without LV hypertrophy ( $\mathrm{n}=36, \mathrm{LV}$ mass $52.2 \pm 10)$, GLS was more markedly decreased to $-15.7 \pm 4.8 \%$ versus -18.5 $\pm 4.2 \%, \mathrm{p}=0.016)$. In contrast, both GRS and GCS were similar between both COA subgroups $(\mathrm{p}=0.49$ and 0.27$)$.

\section{Conclusions}

In patients late after COA repair with normal LV-EF, GLS and GRS are reduced whilst GCS is preserved, compared with controls. GLS is even more reduced in the presence of LV hypertrophy. Longitudinal strain is particularly reduced in basal LV segments. GLS may qualify as indicator of early LV dysfunction if confirmed in prospective outcome studies.

\section{Funding}

None. 


\section{Author details}

${ }^{1}$ Joint Division of Pediatric Cardiology, University of Nebraska College of Medicine/ Creighton University School of Medicine, Children's Hospital and Medical Center, Omaha, NE, USA. ${ }^{2}$ King's College London British Heart Foundation Center of Excellence, National Institute of Health Research Biomedical Research Center at Guy's and St. Thomas' NHS Foundation Trust, Division of Imaging, London, UK. ${ }^{3}$ Depts for Radiology and Paediatric

Cardiology, St Radboud Medisch Universiteit, Nijmegen, Netherlands.

Published: 1 February 2012

doi:10.1186/1532-429X-14-S1-059

Cite this article as: Kutty et al.: Reduced global longitudinal and radial strain with normal left ventricular ejection fraction late after effective repair of aortic coarctation - a CMR feature tracking study. Journal of Cardiovascular Magnetic Resonance 2012 14(Suppl 1):O59.

Submit your next manuscript to BioMed Central and take full advantage of:

- Convenient online submission

- Thorough peer review

- No space constraints or color figure charges

- Immediate publication on acceptance

- Inclusion in PubMed, CAS, Scopus and Google Scholar

- Research which is freely available for redistribution

Submit your manuscript at www.biomedcentral.com/submit 